\title{
Electrochemical Capacitance of Nitrogen-Containing Nanocarbons Prepared Using Porous Anodic Alumina Template
}

\author{
Masahiko Kiriu, Koji Fushimi, Hidetaka Konno, and Hiroki HabAZAKI* \\ Graduate School of Engineering, Hokkaido University (N13-W8, Sapporo 060-8628, Japan)
}

Received October 19, 2007 ; Accepted December 17, 2007

\begin{abstract}
Nanocarbons with brush-type morphology have been prepared by liquid phase carbonization of poly(acrylamide) (PAA) or poly(vinylchloride) (PVC) in pores of template. The template used is dc etched aluminum foil that is further anodized in sulfuric acid electrolyte. The nanocarbons derived from PAA contain nitrogen, whose content decreases with increasing heat treatment temperature. At each heat treatment temperature, the specific surface area as well as pore structure is similar for both the nanocarbons derived from PAA and PVC. Nevertheless, the markedly large electrochemical capacitance, measured in $1 \mathrm{~mol} \mathrm{dm}^{-3}$ sulphuric acid, is obtained for the PAAderived nanocarbons, compared with that from PVC, due to pseudocapacitance arising from nitrogen species in the former nanocarbons. Despite the specific surface area of less than $250 \mathrm{~m}^{2} \mathrm{~g}^{-1}$, the PAA-derived nanocarbons reveal the capacitance as large as $\sim 130 \mathrm{~F} \mathrm{~g}^{-1}$. The capacitance per specific surface area is found to increase almost linearly with the content of nitrogen. It is also found that the capacitance per specific surface area of the nanocarbons with the brush-type morphology is larger than that of the carbon nanofilaments prepared similarly using a template of porous anodic alumina on plain aluminum foil.
\end{abstract}

Key Words : Nano-carbons, Electrochemical Capacitor, Pseudo-capacitance, Template Synthesis

\section{Introduction}

In recent years supercapacitors are attracted considerable attention as energy storage devices with high power density and excellent durability. Activated carbon is the most frequently used electrode materials for supercapacitors. The charge storage is based on the charge separation taking place across a very small distance in an electric double layer. Large capacitance of the activated carbon is associated with the extremely high specific surface area of more than $2000 \mathrm{~m}^{2} \mathrm{~g}^{-1}$, owing to the porous nature of the activated carbon. Since charging and discharging involves simply the movement of ions to and from the electrode surface, the process is inherently rapid. In addition, the supercapacitors reveal excellent cycle stability due to their simple charge storage mechanism.

Surface functional groups of carbon are known to influence largely its double layer properties, such as wettability, point of zero charge, electrical contact resistance, adsorption of ions and self-discharge characteristics. ${ }^{1)}$ Recently, particular interest has been paid to nitrogen species, which enhance markedly the capacitance of carbon materials. Jurewicz et al. have reported the improved supercapacitor performance of activated carbon by ammoxidation.-4) The enhanced capacitance by nitrogen heteroatoms is often explained in terms of faradaic reactions, i.e., pseudocapacitance effect. Lota $e t$ $a l$. have demonstrated a beneficial effect of nitrogen substituted for carbon on the capacitance behaviour of porous carbon in acidic and organic electrolytes. The importance of pore size as well as redox properties of nitrogen-containing nanocarbons prepared using mesoporous silica template for capacitance of the carbon materials is also clearly revealed..5) Further, capacitive behaviour of carbon materials with high nitrogen contents of more than 20 mass \%, which were prepared from melamine resins, has been examined in acidic electrolyte ${ }^{6)}$ as well as in alkaline and organic electrolytes. $\left.{ }^{7}\right)$ Despite the relatively low specific surface area of $400 \mathrm{~m}^{2}$ $\mathrm{g}^{-1}$ or less, the capacitance of $\sim 200 \mathrm{~F} \mathrm{~g}^{-1}$ has been obtained in acidic electrolyte, although in an organic electrolyte, the capacitance is as low as $20-40 \mathrm{~F} \mathrm{~g} \mathrm{~g}^{-1}$. In this manner, nitrogen-substituted carbons are interesting electrode materials for supercapacitors. However, precise mechanism of the enhanced capacitance by nitrogen species has not yet been understood since no obvious redox reactions are observed in cyclic voltammograms.

The authors have prepared carbon nanofilaments (CNFs) using anodic porous alumina template by liquid phase carbonization of polymers. ${ }^{8,9)}$ Some of polymers, such as poly(vinyl chloride) (PVC) and poly(vinyl alcohol) (PVA) form liquefied pitch-like intermediate during heating in an inert atmosphere. ${ }^{10)}$ Thus, by simply heating a mixture of such polymer powders and the porous template, the CNFs have been developed in the pore of the template. The diameters of the CNFs corresponded to the pore size of the template. Further, the CNFs thus formed have a platelet structure; the carbon layers developed are normal to the filament axis. The orientation of this type may be generated from the edge-on interaction of polyaromatic compounds in the liquid phase with the pore wall of the alumina template. ${ }^{11-13)}$ The platelet-type CNFs possess large edge surface. Thus, the materials are of interest as an electrode of electric double layer capacitors, since the capacitance of the edge plane of graphite is significantly larger than 
that of the basal plane. ${ }^{14)}$

Additionally, the template process is suitable to produce the carbon materials with controlled morphology and pore structure, which allow us to investigate the influence of nitrogen species on the electrochemical capacitance of the carbon materials precisely. In the present study, we have prepared nitrogen-containing nanocarbons from poly(acrylamide) (PAA) as well as nitrogen-free nanocarbons from PVC using porous anodic alumina template. The template used in this study has been developed by anodizing of etched aluminium foils, which are used in electrolytic capacitor industry. Thus, the nanocarbons developed have brush-type morphology. ${ }^{15)}$ The capacitance of the nanocarbons has been examined as a function of nitrogen content in the nanocarbons.

\section{Experimental}

\subsection{Preparation of nanocarbons}

Template used in this study was prepared by anodizing of dc etched aluminum foils, approximately $100 \mu \mathrm{m}$ thick, at $25 \mathrm{~V}$ in $0.1 \mathrm{~mol} \mathrm{dm}^{-3}$ sulphuric acid electrolyte at $15{ }^{\circ} \mathrm{C}$ for $1 \mathrm{~h}$. The etched foil, provided from Japan Capacitor Industrial Co., Ltd., Tokyo, Japan, had tunnel pits, $0.2-0.5 \mu \mathrm{m}$ square and more than $40 \mu \mathrm{m}$ length. The porous anodic films grew from the pore wall of the etched foil. The anodizing converted almost entire aluminium foil to porous anodic alumina. After immersion of the anodized foil in $0.1 \mathrm{~mol} \mathrm{dm}{ }^{-3}$ phosphoric acid at $25{ }^{\circ} \mathrm{C}$ for $30 \mathrm{~min}$ for slight pore widening, it was used as a template.

A mixture of PAA (Kishida Chemical Co., Ltd., molecular weight of approximately 16000000) or PVC (TS-500R, Sekisui Chemical Co., Ltd., degree of polymerization of $500)$ powders and the template was heated in an argon stream at $400 \mathrm{~K} \mathrm{~h}^{-1}$ to $300{ }^{\circ} \mathrm{C}$, then kept at this temperature for $30 \mathrm{~min}$. Around this temperature, the polymers were converted to pitch-like liquefied intermediates, penetrating easily into mesopore channels, about $20 \mathrm{~nm}$ in diameter, of the template possibly by capillary flow. The mixture was further heated up to $600{ }^{\circ} \mathrm{C}$ at $400 \mathrm{~K} \mathrm{~h}^{-1}$ and kept at this temperature for $1 \mathrm{~h}$. Then, the template was dissolved in a $10 \% \mathrm{NaOH}$ solution, and the nano-carbon materials were obtained. A part of the nanocarbons were further heat treated at 700 to $1000{ }^{\circ} \mathrm{C}$ for $1 \mathrm{~h}$ in a stream of argon.

\subsection{Characterisation of nanocarbons}

Structure and morphology of the nanocarbons obtained were examined by a JEOL JSM-6500 field emission gun scanning electron microscope operating at $5 \mathrm{kV}$ and a JEOL JEM-2000FX transmission electron microscope operated at $200 \mathrm{kV}$. Nitrogen gas adsorption/desorption isotherms were obtained at $-196{ }^{\circ} \mathrm{C}$ using Bel Japan, Belsorp Mini instrument. From the adsorption isotherms, BET surface areas of the nanocarbons were estimated. Elemental microanalysis was performed to determine the chemical composition of the nanocarbons. Further, X-ray photoelectron spectroscopy (XPS) measurements were carried out to identify the chemical state of nitrogen species. The photoelectron spectra were obtained using Shimadzu ESCA-3200 spectrometer with $\mathrm{Mg} \mathrm{K} \alpha$ radiation. The binding energies of individual species were calibrated using a method described elsewhere. ${ }^{16,17)}$

\subsection{Electrochemical measurements}

The working electrodes for electrochemical measurements were prepared by coating a mixture of the nanocarbons, poly(tetrafluoroethylene) binder (PTFE, E.I. $\mathrm{du}$ Pont de Nemours and Company) and acetylene black (AB, DENKI KAGAKU KOGYO Co., Ltd.) on to titanium mesh current collector. The ratio of the nanocarbons, PTFE and AB was 70: 10: 20 mass \%. Cyclic voltammograms were obtained in deaerated $1 \mathrm{~mol} \mathrm{dm}^{-3} \mathrm{H}_{2} \mathrm{SO}_{4}$ aqueous solution in the potential range of -0.2 to $0.8 \mathrm{~V}$ vs. $\mathrm{Ag} / \mathrm{AgCl}$ at a potential sweep rate of $5-50 \mathrm{mV} \mathrm{s}$. Charge-discharge curves were also obtained in the same electrolyte and potential range at a current density of 0.5 $\mathrm{A} \mathrm{g}^{-1}$

\section{Results and Discussion}

3.1 Preparation and characterisation of nanocarbons

Figure 1 shows a cross-sectional scanning electron micrograph of the porous anodic alumina template used in this study. Vertical pits, 200-500 nm size, developed during dc etching of aluminium are visible in this micrograph. A number of cylindrical pores of 20-30 nm in diameter are grown from the wall of the pits to the approximately horizontal direction in this micrograph. Barrier layers, generally present beneath the pore bottom, are separating pores developed from two adjacent tunnel pits.

Reflecting the pore structure of the template, the nanocarbons prepared from PVC (Fig. 2(a)) and PAA (Fig. 2(b)) reveal brush-type morphology. A number of nanofilaments are disclosed in the scanning electron micrographs, and their diameter is $20-30 \mathrm{~nm}$, corresponding to the size of pores developed by anodizing. The brush-type morphology was more clearly visible from transmission electron micrographs. An example of the transmission electron micrograph of the PAA-derived nanocarbons heat treated at $1000{ }^{\circ} \mathrm{C}$ is shown in Fig. 3. Presence of a core carbon rod of $300 \mathrm{~nm}$ width, which is formed in a tunnel pit of the template, is obvious in this

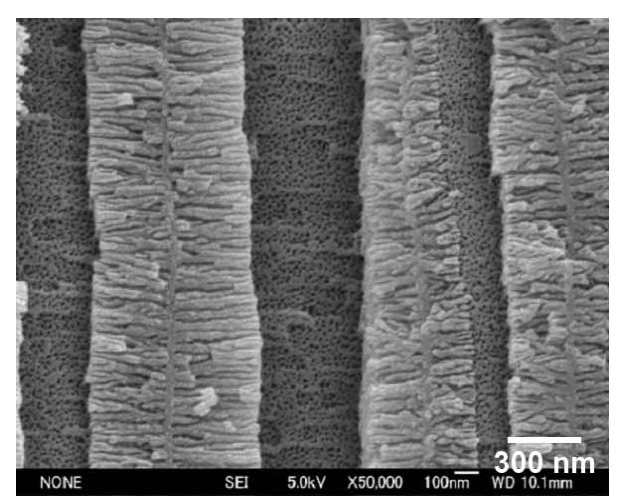

Fig. 1 Scanning electron micrograph of a fractured crosssection of the dc etched aluminium foil after anodizing at 25 $\mathrm{V}$ in $0.1 \mathrm{~mol} \mathrm{dm}^{-3}$ sulphuric acid electrolyte for $1 \mathrm{~h}$. 

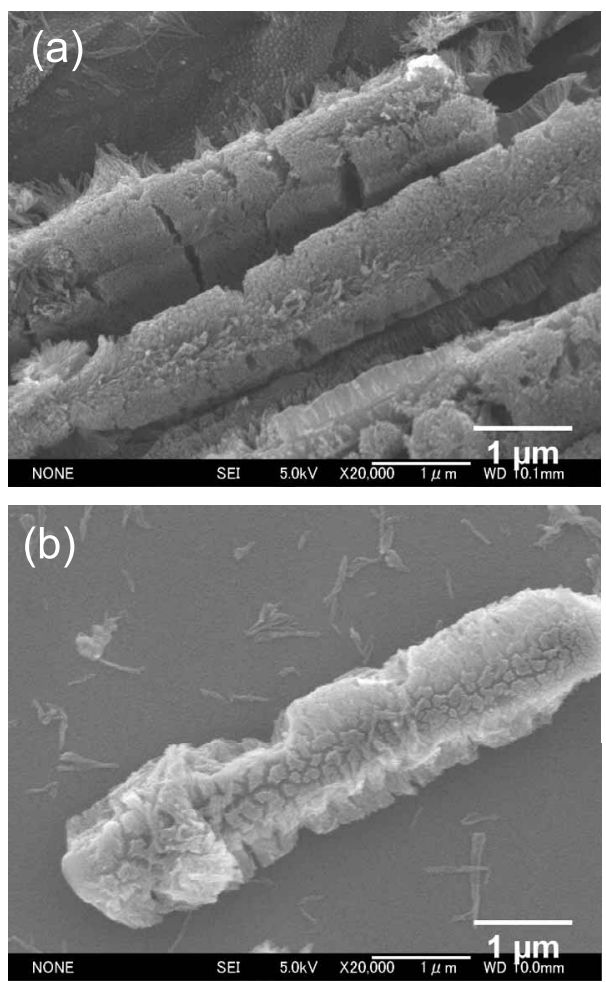

Fig. 2 Scanning electron micrographs of the nanocarbons derived from (a) PVC and (b) PAA after heat treatment at $600{ }^{\circ} \mathrm{C}$.

micrograph. The length of CNFs extending from the core carbon rod is comparable to that of the nanopores in the template (Fig. 1). High resolution image of a CNF part (Fig. 3 (b)) demonstrates the platelet structure, i.e., the carbon layers are normal to the filament axis. Thus, similar to the PVC or PVA-derived CNFs, ${ }^{9,15)}$ platelettype CNFs are developed from a PAA precursor.

The specific surface areas of the nanocarbons prepared in this study are not as large as that of activated carbons $\left(>1500 \mathrm{~m}^{2} \mathrm{~g}^{-1}\right)$, which are often used as an electrode of capacitors. As shown in Fig. 4, the specific surface areas of the PAA- and PVC-derived nanocarbons decrease with an increase in the heat treatment temperature. Even at $600^{\circ} \mathrm{C}$ the specific surface areas are less than $250 \mathrm{~m}^{2} \mathrm{~g}^{-1}$. The areas are similar for the PAA- and PVC-derived nanocarbons heat treated at each temperature. In addition, the adsorption and desorption isotherms for the PAA-derived nanocarbons were essentially the same as that of the PVC-derived one. No mesopores are present in all the nanocarbons prepared, but micropores were present in the nanocarbons, particularly heat treated at lower temperatures. The presence of micropores is consistent with the fact that the specific surface area is larger than the geometrical surface area of the brush-type nanocarbons, which is estimated to be approximately $50 \mathrm{~m}^{2} \mathrm{~g}^{-1}$. Since the adsorption and desorption isotherms of the present brush-type nanocarbons and the carbon nanofilaments prepared under similar conditions $^{8)}$ are similar, the micropores were present mainly in the nanofilament regions of the brush-type carbons.
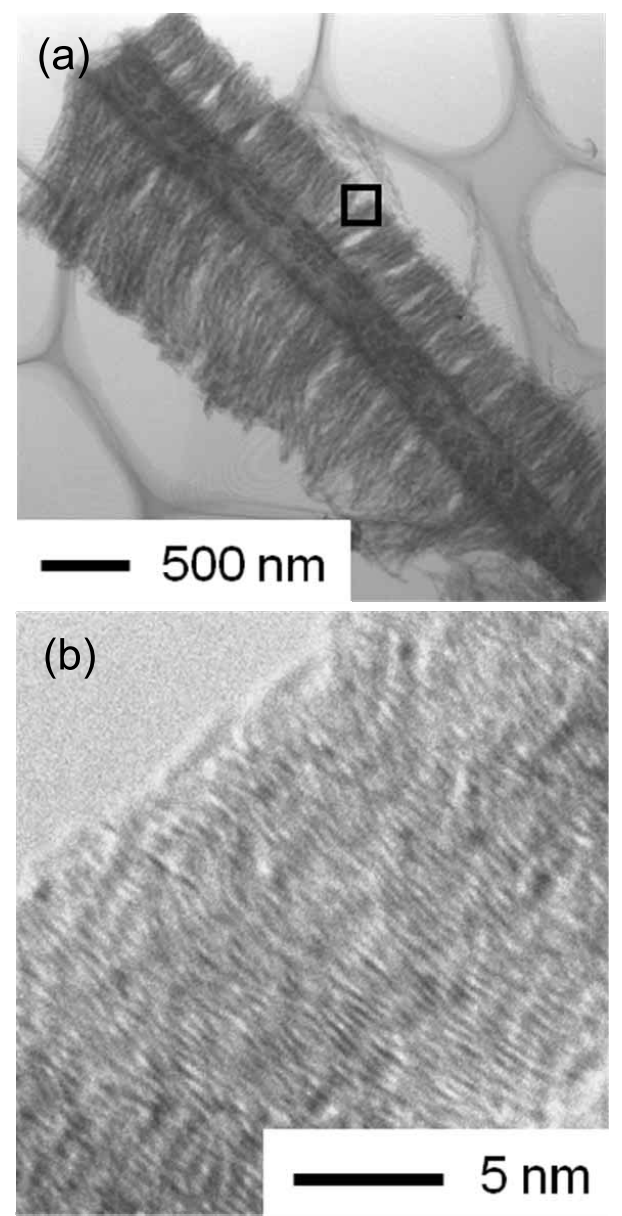

Fig. 3 (a) Transmission electron micrograph of the nanocarbons derived from PAA after heat treatment at $1000^{\circ} \mathrm{C}$. (b) High magnification image of the square region shown in (a).

Although morphology and pore structure for the PAAand PVC-derived nanocarbons are quite similar, the presence of nitrogen species in the PAA-derived nanocarbons has been confirmed by elemental analysis and XPS measurements. Figure 5 shows the change in nitrogen content as well as hydrogen content, determined by elemental analysis, with heat treatment temperature. The nitrogen content is 10.4 mass $\%$ at $600{ }^{\circ} \mathrm{C}$, decreasing with heat treatment temperature. The increased heat treatment temperature also reduces the hydrogen content, since the carbonization proceeds with increasing the temperature.

In order to identify the nitrogen species in the nanocarbons, XPS measurements have been carried out. Figure 6 shows the $\mathrm{N}$ 1s spectra of the PAA-derived nanocarbons heat treated at three different temperatures. The nanocarbons heat treated at $600{ }^{\circ} \mathrm{C}$ reveal two main peaks at 398.0 and $400.0 \mathrm{eV}$. After heat treatment at higher temperatures, an additional peak at $401.9 \mathrm{eV}$ appears, and the peak at $400.0 \mathrm{eV}$ shifts $0.3 \mathrm{eV}$ to higher binding energy with increasing heat treatment temperature. From the previous XPS studies, ${ }^{18-22)}$ the lowest binding energy peak of $398.0 \pm 0.2 \mathrm{eV}$ can be assigned for pyridinic nitrogen. The peak at $400.0-400.3 \mathrm{eV}$ is for pyrrolic nitrogen, and the highest binding energy peak 


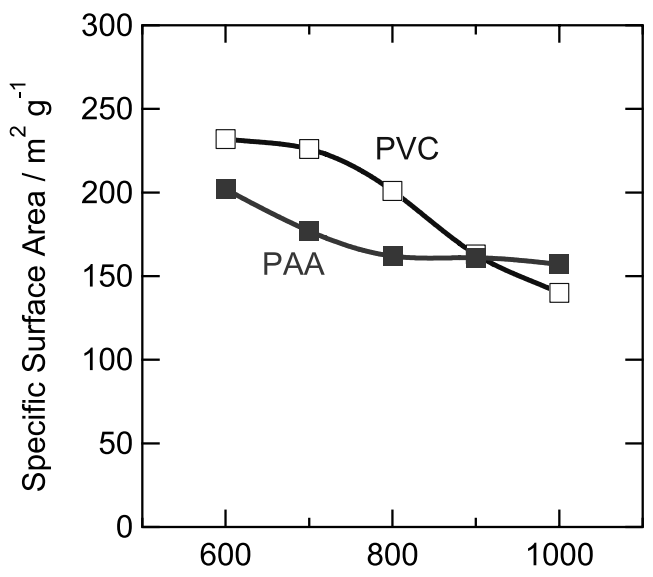

Heat Treatment Temperature $/{ }^{\circ} \mathrm{C}$

Fig. 4 Change in specific surface area of the nanocarbons derived from PAA and PVC with heat treatment temperature.

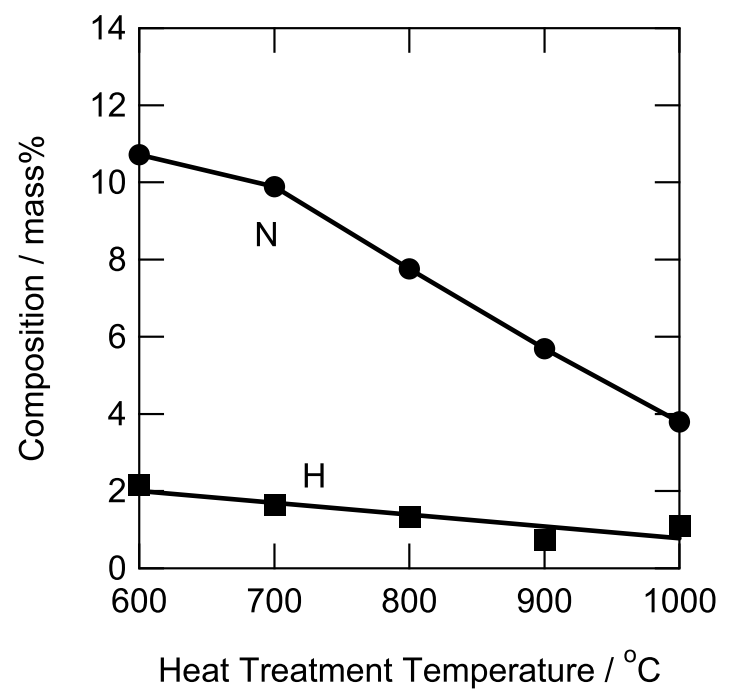

Fig. 5 Change in nitrogen and hydrogen contents in the PAA-derived nanocarbons with heat treatment temperature.

at $401.9 \pm 0.2 \mathrm{eV}$ corresponds to the nitrogen substituents in aromatic graphene layers or quaternary nitrogen species. Thus, the nitrogen-substituted graphene layers appear to be developed at higher temperatures at and above $800{ }^{\circ} \mathrm{C}$. With increasing heat treatment temperature, the intensities of pyridinic and pyrrolic nitrogen species decrease, in agreement with the results shown in Fig. 5. The reduction of the intensity with increased temperature is more significant for the pyridinic nitrogen species than for the pyrrolic nitrogen. Further, from XPS analyses, it was found that the content of oxygen species associated with the carbon materials was negligible at all heat treatment temperatures.

\subsection{Electrochemical characteristics}

Cyclic voltammograms of the nanocarbons heat treated at each temperature (Fig. 7) disclose clearly the higher capacitance of the PAA-derived nanocarbons compared with the PVC-derived ones. Since specific surface areas as well as pore structures are not largely different

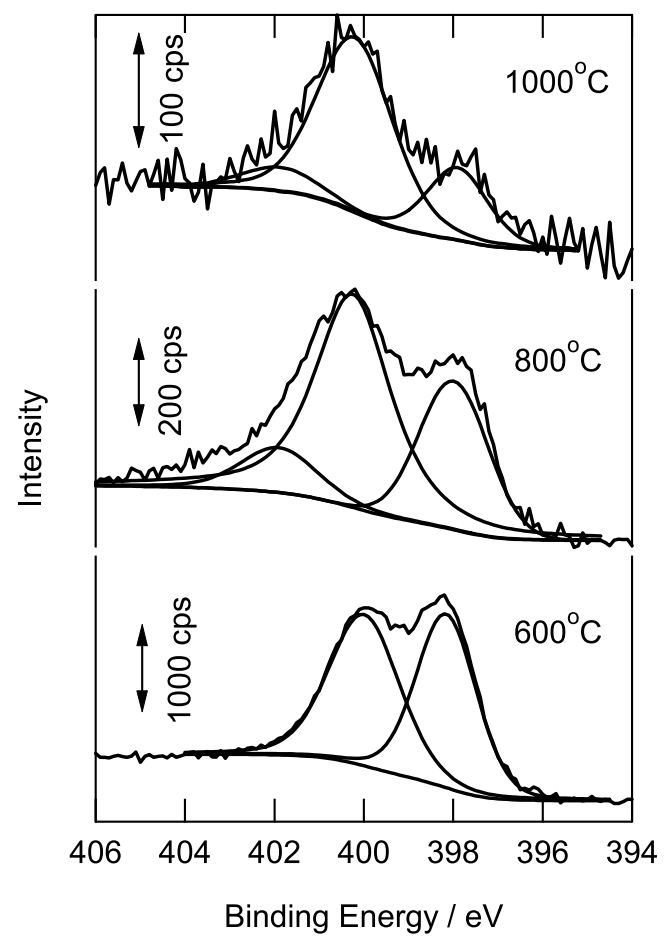

Fig. $6 \mathrm{~N}$ 1s X-ray photoelectron spectra of the PAAderived nanocarbons heat treated at 600,800 and $1000{ }^{\circ} \mathrm{C}$.

for both the nanocarbons at each heat treatment temperature, the enhanced capacitance of the PAA-derived nanocarbons should be attributed to the pseudocapacitance of nanocarbons. At all three temperatures, the rectangular voltammographs are obtained for the PVCderived nanocarbons, while the voltammographs showing higher capacitance below $0.5 \mathrm{~V}$ vs. $\mathrm{Ag} / \mathrm{AgCl}$ are obtained for the PAA-derived nanocarbons heat treated at 600 and $800{ }^{\circ} \mathrm{C}$. Even for the PAA-derived nanocarbons, a voltammogram with fairly rectangular shape is developed after heat treatment at $1000{ }^{\circ} \mathrm{C}$.

The capacitances of the PAA- and PVC-derived nanocarbons are summarised in Table 1 . From both the $\mathrm{CV}$ measurements and charge-discharge curves, similar capacitances were obtained. The PAA-derived nanocarbons heat treated at $600{ }^{\circ} \mathrm{C}$ shows the highest capacitance among the nanocarbons examined. The capacitance value is as large as $130 \mathrm{~F} \mathrm{~g}^{-1}$.

It is obvious from Fig. 7 and Table 1 that the capacitance decreases with increased heat treatment temperature, particularly for the PAA-derived nanocarbons. The reduced capacitance should be associated mainly with the decrease in the specific surface area (Fig. 4) for both the PAA- and PVC-derived nanocarbons, in addition to the reduced nitrogen content for the PAA-derived nanocarbons. In order to clarify the influence of nitrogen species on the capacitance, the capacitance per surface area is plotted as a function of the nitrogen content (Fig. 8). The capacitances of the PAA- and PVC-derived nanocarbons heat treated at the three different temperatures are all plotted in this figure. There is a good correlation between the capacitance and the nitrogen content for the PAA-derived nanocarbons; the capacitance increases almost linearly with the nitrogen content. The 

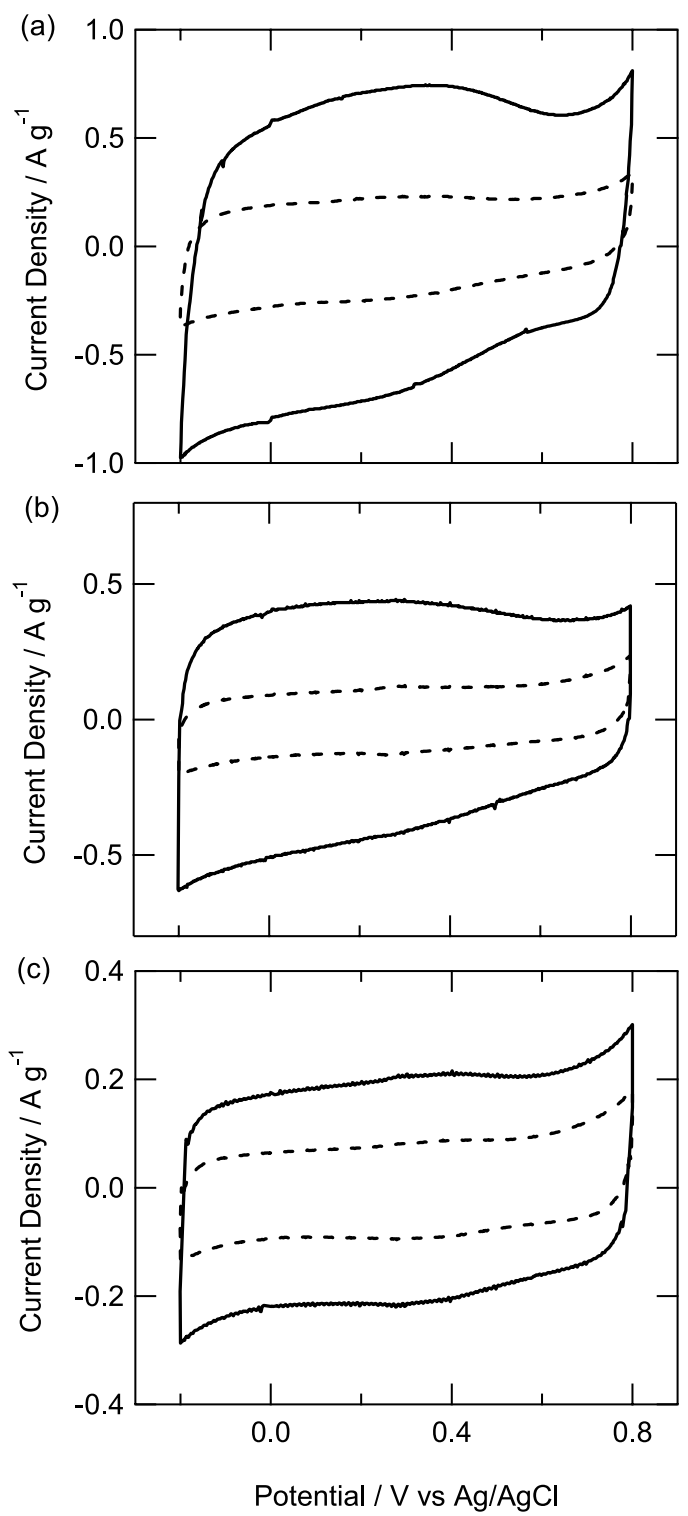

Fig. 7 Cyclic voltammograms of the PAA (solid line)- and PVC (dashed line)-derived nanocarbons heat treated at (a) 600, (b) 800 and (c) $1000{ }^{\circ} \mathrm{C}$, measured in $1 \mathrm{~mol} \mathrm{dm}{ }^{-3}$ sulphuric acid electrolyte.

result should indicate that nitrogen species in the nanocarbons contribute to the enhanced capacitance. However, from XPS analysis, the fraction of each nitrogen species does not change linearly with the total nitrogen content. These findings suggest that the enhanced capacitance is not associated with merely one of these nitrogen species. In Fig. 8, extrapolation of the linear correlation to the nitrogen content of 0 mass $\%$ corresponds to those for the PVC-derived nanocarbons, confirming that the nitrogen species enhance the capacitance. The capacitance of the PVC-derived nanocarbons (15-20 $\mu \mathrm{F}$ $\mathrm{cm}^{-2}$ ) is similar to that of typical activated carbons. ${ }^{23)}$ Thus, there is no beneficial effect of the high edge surface of the platelet structure nanocarbons, possibly due to low graphitisation degree of the carbon materials.

Although the PAA-derived nanocarbons heat treated at $600{ }^{\circ} \mathrm{C}$ shows the highest capacitance, the capacitance decreases largely as the sweep rate increases in the $\mathrm{CV}$
Table 1 Capacitances of the nanocarbons prepared from PAA and PVC after heat treatment at three different temperatures.

\begin{tabular}{ccc}
\hline Precursors & $\begin{array}{c}\text { Heat treatment } \\
\text { temperature }\left({ }^{\circ} \mathrm{C}\right)\end{array}$ & $\begin{array}{c}\text { Capacitance } \\
\left(\mathrm{F} \mathrm{g}^{-1}\right)^{*}\end{array}$ \\
\hline PAA & 600 & 123 \\
& 700 & 97 \\
& 800 & 78 \\
& 900 & 52 \\
& 1000 & 39 \\
PVC & 600 & 42 \\
& 800 & 23 \\
& 1000 & 18 \\
\hline
\end{tabular}

*The values were obtained from $\mathrm{CV}$ curves with a sweep rate of $5 \mathrm{mV} \mathrm{s}^{-1}$.

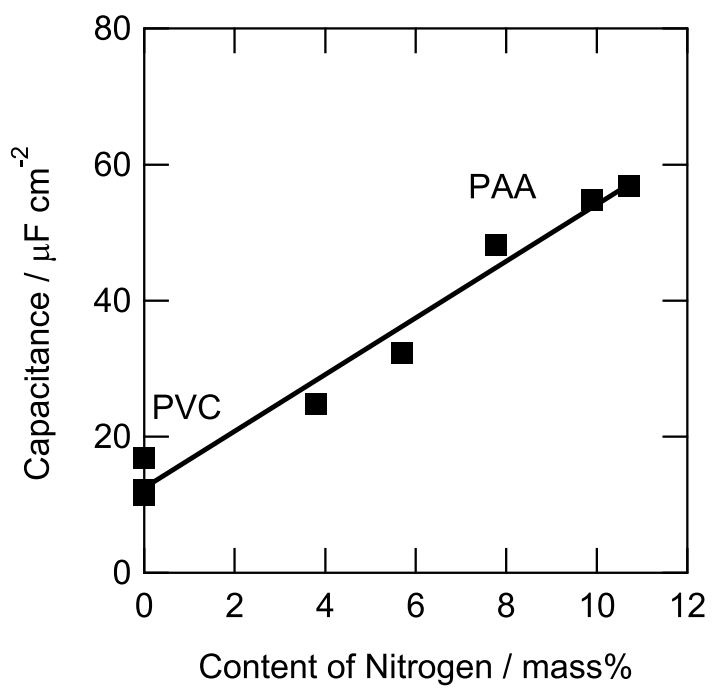

Fig. 8 Change in the capacitance per specific surface area of the PAA- and PVC-derived nanocarbons with the content of nitrogen.

measurements (Fig. 9). The reduction of the capacitance with sweep rate becomes less significant with increasing heat treatment temperature. One of the reasons may be increased electric conductivity of the nanocarbons heat treated at higher temperatures. This is partly supported by the fact that at higher sweep rates the cyclic voltammograms were no longer rectangular. The smaller change in the capacitance with sweep rate for the PVCderived nanocarbons compared with the PAA-derived counterpart may be also due to different electrical conductivity, which arises from the different carbonization behaviour of the polymers. ${ }^{24)}$

However, the PAA-derived nanocarbons heat treated at $600{ }^{\circ} \mathrm{C}$ demonstrate the good cycle stability (Fig. 10). The high capacitance of $\sim 130 \mathrm{~F} \mathrm{~g}^{-1}$ is sustained up to 1000 cycles examined. The nitrogen functional species are stably present during the cycle examination, and Faradaic redox reactions occur repeatedly without degradation.

Finally, in order to confirm whether brush-type morphology is beneficial for capacitor characteristics, the $\mathrm{CV}$ measurements of simple CNFs prepared from PAA at 
$600{ }^{\circ} \mathrm{C}$ were carried out. The CNFs were prepared using porous anodic alumina template developed on plain aluminium foils without tunnel pits. The capacitance per specific surface area for the CNFs was $39 \mu \mathrm{F} \mathrm{cm}-2$, being lower than that of the brush-type ones formed at the same temperature $\left(57 \mu \mathrm{F} \mathrm{cm}{ }^{-2}\right)$. Since the nitrogen contents of both the samples were similar, the higher capacitance of the brush-type nanocarbons may be originated from this unique morphology. A number of CNFs are connected to a carbon rod of $200-500 \mathrm{~nm}$ for the brushtype one. Such morphology should be beneficial in terms of the electronic conduction compared with the separated carbon nanofilaments. However, further detailed study is awaited to elucidate the beneficial role of the brush-type morphology on the capacitive behavior.

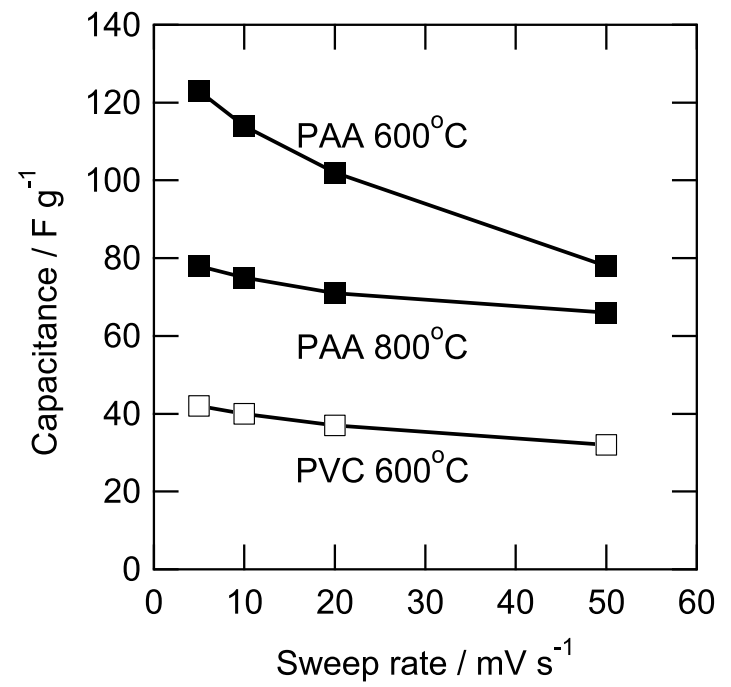

Fig. 9 Sweep rate dependence of the capacitance of the PAA-derived nanocarbons heat treated at 600 and $800{ }^{\circ} \mathrm{C}$ and of the PVC-derived nanocarbons heat treated at $600{ }^{\circ} \mathrm{C}$.

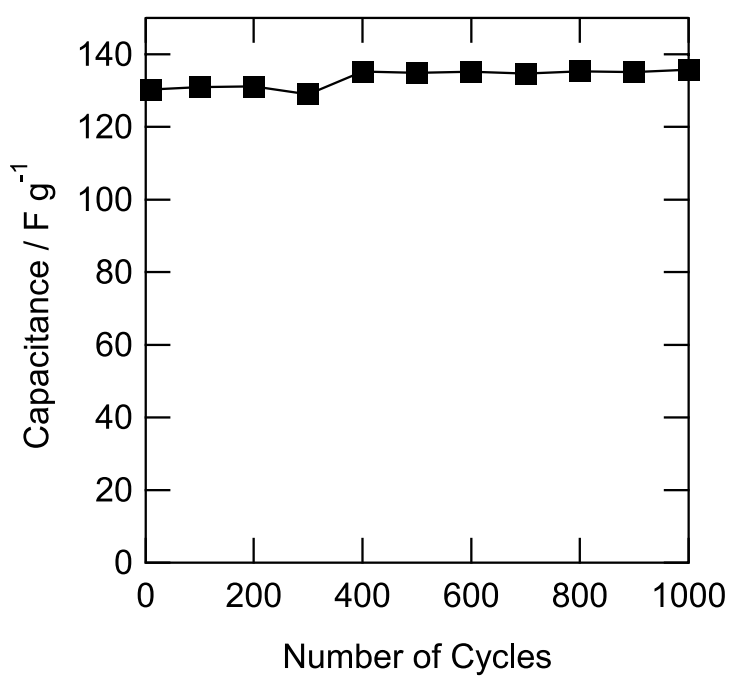

Fig. 10 Cycle stability of the capacitance of the PAAderived nanocarbons heat treated at $600{ }^{\circ} \mathrm{C}$. The capacitance was measured by repeated galvanostatic charge-discharge measurements in $1 \mathrm{~mol} \mathrm{dm}^{-3}$ sulphuric acid electrolyte at a current density of $0.5 \mathrm{~A} \mathrm{~g}^{-1}$.

\section{Conclusions}

Using morphologically well-defined nanocarbons that are prepared by a template technique, influence of nitrogen species in the nanocarbons in electrochemical capacitance can be examined precisely. The capacitance per specific surface area of the nanocarbons, prepared from PAA, with brush-type morphology increases approximately linearly with the nitrogen content. Surface functional nitrogen species and pyrrolic nitrogen are mainly present in the nanocarbons. The capacitance decreases with increasing heat treatment temperature, due to the reduced specific surface area as well as reduced nitrogen content, but the rate characteristics is improved at high heat treatment temperatures.

\section{References}

1) B. E. Conway, Electrochemical supercapacitors : scientific fundamentals and technological applications, New York: Prenum Press (1999).

2) K. Jurewicz, K. Babel, A. Ziolkowski, H. Wachowska, and M. Kozlowski, Fuel Processing Technology, 77, 191 (2002).

3) K. Jurewicz, K. Babel, A. Ziolkowski, and H. Wachowska, Electrochim. Acta, 48, 1491 (2003).

4) K. Jurewicz, K. Babel, A. Ziolkowski, and H. Wachowska, J. Phys. Chem. Solids, 65, 269 (2004).

5) E. Frackowiak, G. Lota, J. Machnikowski, C. Vix-Guterl, and F. B'eguin, Electrochim. Acta, 51, 2209 (2006).

6) D. Hulicova, J. Yamashita, Y. Soneda, H. Hatori, and M. Kodama, Chem. Mater., 17, 1241 (2005).

7) D. Hulicova, M. Kodama, and H. Hatori, Chem. Mater., 18, 2318 (2006).

8) H. Habazaki, M. Kiriu, M. Hayashi, and H. Konno, Mater. Chem. Phys., 105, 367 (2007).

9) H. Konno, S. Sato, H. Habazaki, and M. Inagaki, Carbon, 42, 2756 (2004).

10) H. Konno, K. Oyamada, and M. Inagaki, J. Eur. Ceram. Soc., 20, 1391 (2000).

11) K. Jian, H.-S. Shim, A. Schwartzman, G. P. Crawford, and H. Hurt, Adv. Mater., 15, 164 (2003).

12) C. Chan, G. Crawford, Y. M. Gao, R. Hurt, K. Q. Jian, H. Li, B. Sheldon, M. Sousa, and N. Yang, Carbon, 43, 2431 (2005).

13) R. Hurt, G. Krammer, G. Crawford, K. Jian, and C. Rulison, Chem. Mater., 144558 (2002).

14) J. P. Randin and E. Yeager, J. Electroanal. Chem., 58, 313 (1975).

15) H. Habazaki, M. Hayashi, H. Konno, and M. Inagaki, $J$. Surf. Finish. Soc. Jpn, 56, 352 (2005).

16) K. Asami, J. Electron Spectrosc. Relat. Phenom., 9, 469 (1976).

17) K. Asami and K. Hashimoto, Corros. Sci., 17, 559 (1977).

18) R. J. J. Jansen and H. Vanbekkum, Carbon, 33, 1021 (1995).

19) K. Stanczyk, R. Dziembaj, Z. Piwowarska, and S. Witkowski, Carbon, 33, 1383 (1995).

20) J. R. Pels, F. Kapteijn, J. A. Moulijn, Q. Zhu, and K. M. Thomas, Carbon, 33, 1641 (1995).

21) S. Biniak, G. Szymanski, J. Siedlewski, and A. Swiatkowski, Carbon, 35, 1799 (1997).

22) F. Kapteijn, J. A. Moulijn, S. Matzner, and H. P. Boehm, Carbon, 37, 1143 (1999).

23) T. A. Centeno and F. Stoeckli, Electrochim. Acta, 52, 560 (2006)

24) D. Dollimore and G. R. Heal, Carbon, 5, 65 (1967). 